IdeAs

Idées d'Amériques

$15 \mid 2020$

Eau et gestion de l'eau dans les Amériques

\title{
Nueva Constitución y proceso constituyente
}

\section{María Cristina Escudero Illanes y Jaime Gajardo Falcón}

\section{(2) OpenEdition}

\section{Journals}

Edición electrónica

URL: http://journals.openedition.org/ideas/8417

DOI: 10.4000/ideas.8417

ISSN: 1950-5701

Editor

Institut des Amériques

Referencia electrónica

María Cristina Escudero Illanes y Jaime Gajardo Falcón, « Nueva Constitución y proceso constituyente », IdeAs [En línea], 15 | 2020, Publicado el 01 marzo 2020, consultado el 25 marzo 2020. URL : http:// journals.openedition.org/ideas/8417 ; DOI : https://doi.org/10.4000/ideas.8417

Este documento fue generado automáticamente el 25 marzo 2020.

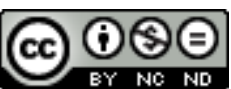

IdeAs - Idées d'Amériques est mis à disposition selon les termes de la licence Creative Commons Attribution - Pas d'Utilisation Commerciale - Pas de Modification 4.0 International. 


\title{
Nueva Constitución y proceso constituyente
}

\author{
María Cristina Escudero Illanes y Jaime Gajardo Falcón
}

1 Los procesos constituyentes en democracia son hitos que demoran en concretarse, principalmente porque deben ser fruto de un amplio consenso social y político. En el caso de Chile, el consenso social fue adquiriendo fuerza a partir de las primeras movilizaciones estudiantiles de 2006, hasta constituirse en una de las principales demandas en el 2019. Las encuestas han mostrado un apoyo consistente al reemplazo de la constitución de 1980 por parte de la opinión pública. Por ejemplo, en el 2016, un $56 \%$ de los encuestados se manifestó a favor de una nueva Constitución, mientras que en la encuesta CEP de enero de 2019, un 67\% está de acuerdo con reemplazar la Constitución. El principal problema para iniciar el proceso constituyente no ha sido el acuerdo social, sino político. Han sido los partidos políticos con representación parlamentaria, los que no habían logrado un acuerdo ni en querer reemplazar la Constitución, ni menos en el mecanismo para hacerlo. Por ello, el acuerdo "por la Paz y una Nueva Constitución", firmado el 15 de noviembre de 2019 entre 11 de las 14 fuerzas políticas presentes en el Congreso, constituye el primer paso para iniciar este camino.

2 El presente artículo revisará, en primer lugar, los principales aspectos que ha sistematizado la doctrina constitucional chilena para señalar el por qué se requiere de una nueva constitución. En segundo lugar, daremos cuenta de los puntos centrales del proceso constituyente que se ha aprobado en el Congreso Nacional. Finalmente, el trabajo tendrá algunas conclusiones sobre el proceso constituyente que Chile ha comenzado a transitar y sus principales desafíos.

\section{¿Por qué es necesaria una nueva Constitución?}

3 Las principales críticas que ha recibido la Constitución Política de 1980 se han sistematizado en tres ejes fundamentales, que se encuentran relacionados entre sí: 1) el origen autoritario de la Constitución y su imposibilidad para legitimarla; 2) el establecimiento de un sistema democráticamente deficitario ${ }^{1}$; 3) la opción ideológica 
neoliberal de la Constitución y, en consecuencia, la débil consagración de derechos económicos y sociales (Busch, T., 2012: 1-3).

Respecto a la primera crítica, la doctrina constitucional chilena comparte que el origen autoritario de la Constitución es un problema capital de la misma (con distintos matices). Las divergencias surgen con respecto a su imposibilidad de legitimarse en el tiempo. En este punto, Francisco Zúñiga señala que las reformas a la Constitución y, principalmente, las realizadas en el año 2005 han permitido una "cierta" legitimidad de la misma pero no total y que dicho camino se encuentra agotado (Zúñiga F., 2013: 515-516). Atria arriba a la misma conclusión que Zúñiga pero a través de una argumentación diferente. Para él, el "pecado de origen" de la Constitución no es el asunto principal, sino que es la imposibilidad que tiene el pueblo de ejercer su poder en el marco constitucional y, en consecuencia, de apropiarse de la misma o dicho en otros términos, de "legitimarla" (Atria, F., 2013, pp. 58-63). Por su parte, para Ruiz-Tagle las reformas realizadas a la Constitución en el año 2005 permitieron atenuar la filosofía del constitucionalismo autoritario y abrir espacios para el cambio constitucional (RuizTagle, P. 2006: 80-81).

5 Por su parte, el déficit democrático de la Constitución y sus recursos contra mayoritarios la vuelven "intocable" en sus aspectos sustanciales. Los principales mecanismos constitucionales contra-mayoritarios y que tienden a la neutralización del autogobierno colectivo son: 1) las leyes de "súper mayorías" (interpretativas de la Constitución, orgánicas constitucionales y de quórums calificados); 2) el control preventivo de Constitucionalidad que realiza el Tribunal Constitucional y su práctica jurisprudencial; 3) la rigidez y altos quórums para la reforma a la Constitución. Así los autores hablan de Constitución "celda" (Suarez, Ch., 2009: 248-271), de la Constitución "tramposa" (Atria, F., 2013: 44-56) y de democracia "protegida" (Cazor, K., 2007: 45-74).

6 A los argumentos señalados, se han ido planteado tres nuevos cuestionamientos, los que han sido formulados (o reformulados) de forma más reciente y son aspectos atribuibles a una tendencia general del constitucionalismo chileno, aunque han sido acentuados en la Constitución vigente. Estos aspectos son: 1) la visión mono cultural y nacional de la Constitución, en la cual no se reconoce el carácter multicultural de la sociedad chilena y, en particular, a los pueblos indígenas que habitan en el territorio; 2) el excesivo centralismo territorial que imprime la actual Constitución al diseño institucional; 3) el diseño híper presidencialista y el fenómeno de concentración del poder.

7 Sobre los cuestionamientos expuestos, consideramos relevante realizar tres anotaciones. La primera, tiene relación con su transversalidad debido a la estructura de la Constitución, es decir, estas objeciones abarcan todas las partes de esta (dogmática y orgánica). En segundo lugar, las críticas operan en múltiples planos, tanto en sus aspectos políticos (por ejemplo, legitimidad de origen), económicos (la consagración del neoliberalismo), sociales (el déficit democrático o híper presidencialismo), culturales (falta de reconocimiento de la diversidad cultural) y territoriales (el exceso de centralismo). Como tercer aspecto, todas las críticas reseñadas se pueden constatar, con diferencias de grado, desde la vigencia de la Constitución Política hasta la actualidad, a pesar de las múltiples reformas que ésta ha experimentado.

8 A pesar de lo anterior, los gobiernos de la ex Concertación y de la Nueva Mayoría, buscaron a través de reformas legales ir dando respuestas a las demandas de la ciudadanía por un país más igualitario. El Tribunal Constitucional se ha vuelto una 
barrera casi infranqueable para los proyectos de ley que buscan hacer realidad los anhelados cambios sociales de Chile. Así, entre otros el Tribunal Constitucional declaró la inconstitucionalidad de la titularidad sindical en la "reforma laboral", la circulación de la "píldora del día después" y la glosa de gratuidad en la educación. El Tribunal Constitucional fue ideado como un guardián del diseño institucional e ideológico impuesto en la dictadura que en la práctica se ha erigido como una "tercera cámara", una especie de legislador negativo destinado a bloquear el autogobierno colectivo. El Tribunal Constitucional se ha atrincherado en una interpretación originalista de una Constitución ilegítima, resguardando el principio de subsidiariedad en lo económico y las concepciones conservadoras en lo valórico. Todo ello ha permitido sumar ingredientes al descontento social y a la crisis constitucional.

\section{Principales hitos del proceso constituyente}

9 El proceso constituyente se institucionalizó a través de una reforma constitucional que introdujo un párrafo "Del Procedimiento para elaborar una Nueva Constitución Política de la República" al capítulo XV, con 14 nuevos artículos. Se trata de un proceso en tres actos: un plebiscito de entrada, un periodo de deliberación a través de una Convención y un plebiscito ratificatorio final. Los hitos del proceso se pueden leer bajo tres principios que explican las características básicas del proceso: a) participación e integración, b) certezas y c) limitaciones y autonomía.

\section{Participación e integración de ambas convenciones}

Pese a que el proceso constituyente es un acuerdo político, este se definirá a través de un excepcional mecanismo de participación ciudadana directa. En efecto, el 26 de abril habrá un plebiscito en el cual se harán dos preguntas. La primera de ellas es para definir si se aprueba o rechaza una nueva constitución. En una papeleta aparte se le consultará a la ciudadanía por el mecanismo que prefiere: una convención mixta (CM) o una convención constitucional (CC). Este plebiscito refleja el desacuerdo de las elites políticas. En primer lugar, el frágil convencimiento de los partidos de derecha de remplazar la constitución y, en segundo lugar, la opción de este mismo sector de tener una convención integrada por $50 \%$ de parlamentarios y $50 \%$ de ciudadanos electos (CM), mientras la centro izquierda propone una convención 100\% elegida por la ciudadanía (CC).

11 El acuerdo del 15 de noviembre de 2019 estableció que la elección a los convencionales constituyentes se haría por las mismas reglas que se eligen a los diputados. Esto implicó que en principio serán 155 integrantes de la Convención (al igual que la Cámara Baja). Sin embargo, para salvaguardar el principio de proporcionalidad electoral en el caso de la Convención mixta, se debieron ajustar los distritos para que en cada uno de ellos se eligieran a lo menos 2 personas. Esta es la razón por la cual la CM tendría 172 integrantes, donde 86 serían elegidos por el Congreso y los otros 86 por la ciudadanía.

Por otra parte, la edad para ser convencional se rebajó de 21 para ser diputados a 18 y se permitió que los dirigentes sindicales pudiesen ser candidatos, cosa vedada para las candidaturas parlamentarias. Se establecieron también algunas incompatibilidades para altos cargos de la administración pública, como ministros, intendentes, alcaldes, entre otros y se estableció la suspensión del cargo para funcionarios de menor grado. 
Asimismo, se estableció una remuneración de 50 UTM mensuales (\$2.5 millones) para quienes integren la convención, a excepción de los parlamentarios en la comisión mixta, quienes conservarán su remuneración parlamentaria.

Finalmente, la participación también se manifestará en el plebiscito de ratificación, una vez que la convención redacte su propuesta. Esta es la única instancia de voto obligatorio durante todo el proceso, ya que la centro-derecha fue escéptica a incorporarlo en el acuerdo para las demás elecciones del proceso. El plebiscito ratificatorio deberá realizarse 60 días después de terminado el trabajo de la convención para dar tiempo de la aprehensión por parte de la ciudadanía, y no debe coincidir con los meses de enero y febrero (meses de vacaciones)

\section{Certezas del proceso}

Uno de los grandes enemigos de todo proceso constituyente es el grado de incerteza que se produce respecto a aquellos procedimientos regulares para la toma de decisiones. Esto se debe a que generalmente el contexto introduce nuevos actores con incentivos diversos a los habituales y reglas de toma de decisiones diferentes que no han generado patrones de comportamiento predecibles en quienes participan de la deliberación constitucional. En el caso de Chile, existen sectores importantes en las estructuras de poder que aun valoran el status quo por sobre el cambio constitucional y por ello, la incerteza aumenta, para ellos, los costos de la futura convención.

Esta es la razón por la que el acuerdo político necesitó introducir elementos de procedimiento que otorgaran ciertas garantías, especialmente a aquellos sectores más conservadores por un lado, pero también para construir un nuevo pacto social y con ello ir reconstruyendo la paz social. En este contexto se establecieron algunos criterios que le dan contención a la convención. El primero de ellos es el plazo de 9 meses para llevar a cabo su tarea, renovable por tres meses adicionales. Como la finalidad es llegar a un acuerdo de texto, no se establecieron requisitos especiales para lograr dicha prórroga además de la solicitud por el presidente de la convención o un tercio de sus miembros.

Adicionalmente, en el acuerdo político se estableció que las normas debían ser aprobadas por dos tercios de los miembros de la convención, quienes deben trabajar sobre una hoja en blanco. Esta parte del acuerdo ha generado amplio debate sobre su conveniencia. Se la ha justificado señalando, que los dos tercios generan la necesidad de un acuerdo amplio cuyo efecto inmediato es la moderación de las decisiones, puesto que el tercio en cada extremo del espectro político difícilmente podrán imponer sus visiones. Sin embargo, también es cierto que pueden generar lentitud y estancamiento para lo cual se requieren mecanismos de solución de controversias al interior de la convención que quedaron entregadas al reglamento (el cual también debe ser aprobado por 2/3). La hoja en blanco significa que el texto sobre el cual se trabaja no es la Constitución de 1980 y, por lo tanto, su texto no queda vigente en caso que no haya acuerdo en la materia que se discute. Esto impide el bloqueo de quienes no quieren cambiar la actual normativa. En suma, que no haya acuerdo significa que no hay norma sobre ese punto y que puede ser materia de decisión legislativa posterior $\mathrm{u}$ otra solución que la Convención decida a través de su reglamento.

17 Por último, continuará rigiendo la constitución de 1980 en tres situaciones. Que en el plebiscito de entrada gane la opción rechazo. Que la Convención al cabo de un año no 
logre consensuar un texto y si en el plebiscito de ratificatorio ganare la opción "no apruebo la nueva constitución". Para que se discuta la posibilidad de un nuevo proceso constituyente, tendría que existir un nuevo pacto constitucional que habilite el procedimiento que ahora sí estará en la Constitución.

\section{Limitaciones y autonomía}

18 En democracia los procesos constituyentes no ocurren en el vacío. Por el contrario, coexisten con él el arreglo institucional que respeta el pluralismo y ordenamiento vigente (incluyendo la constitución que se quiere reemplazar). Es por ello, que en el procedimiento se enfatiza el respeto por las autoridades electas e instituciones en funcionamiento que la Convención no podría intervenir, aludiendo a su poder originario. En suma, lo único que se le permite a la Convención es la redacción de un texto constitucional para ser sometido a plebiscito ratificatorio.

Relacionado con lo anterior se establecen ciertos márgenes para la acción de la Convención. Así, el texto de nueva constitución no puede vulnerar los principios de la democracia y la organización de república, y debe respetar tanto las sentencias firmes y ejecutoriadas como los tratados internacionales vigentes y ratificados por Chile. La razón que se tuvo a la vista para esta disposición fue garantizar un no retroceso en términos de orden político y derechos, así como la utilización de los canales institucionales constituidos y reconocidos por el derecho internacional para afectar las sentencias y los tratados. Sin embargo, se han levantado críticas a esta limitación por cuanto establecería límites sustantivos confusos e interpretables al mandato de la convención que pudiesen ser utilizados para mantener algunas consecuencias de la aplicación de la Constitución del 1980.

Por último, así como la Convención no puede vulnerar la competencia de otras instituciones, otras instituciones no pueden restar autonomía a la Convención. En este sentido, se habilitó la competencia de un solo organismo externo para conocer de asuntos de la convención. Se trata de una reclamación para asuntos solamente procedimentales y que será conocido por cinco integrantes de la Corte Suprema sorteados para cada caso. Esta instancia solo puede anular el acto que ha faltado a los procedimientos, pero no puede pronunciarse sobre su contenido. De esta manera en lo sustancial la Convención también salva su autonomía para hacer la deliberación correspondiente.

\section{Conclusiones}

Las razones por las cuales se ha esgrimido que se necesita una nueva Constitución son de diverso orden y no se limitan a su ilegitimidad de origen, por el contrario, hay problemas en su aceptación posterior por la forma deficitaria de concebir la democracia (especialmente por el diseño híper presidencialista contra-mayoritario), la visión ideológica que establece, afectando la forma en cómo se consagran y protegen los derechos económicos y sociales y su visión cultural y territorialmente excluyente.

Por otro lado, el proceso hasta ahora acordado ha generado márgenes de certezas y limitaciones a los actores políticos menos inclinados a eliminar el status quo y de autonomía y participación para los sectores políticos que han empujado el reemplazo constitucional por más tiempo. Sin perjuicio de ello, aún quedan algunos aspectos de 
legitimación importantes que resolver para responder a la demanda de la ciudadanía. En primer lugar, aun no hay acuerdo político por la inclusión de independientes, cuotas de pueblos indígenas y equilibrio de género (paridad). Aunque es probable que haya un acuerdo en este sentido en el Congreso, ya hay varios partidos de independientes en formación para presentar candidatos a la convención que no ha esperado a que esto suceda para abrirse un espacio. En segundo lugar, aún faltan procedimientos para vincular a la ciudadanía a través de audiencias o cabildos, con la convención. Si bien parte de esto puede considerarse en el reglamento, si se quiere sistematizar la participación para que sea incidente en la toma de decisiones, se requiere de planificación metodológica y tiempo de implementación.

\section{BIBLIOGRAFÍA}

Atria, Fernando, La Constitución tramposa, Santiago, Lom Ediciones, 2013.

Busch, Tania, « El Concepto de Constitución y la Incomodidad Constitucional en Chile », Global Jurist, vol. 12, 2012, p. 1-38.

Cazor, Kamel, « Constitucionalismo y umbral democrático en Chile: Hacia una nueva teoría constitucional », Ius et Praxis, $n^{\circ} 13,2007$, p. 45-74.

Ruiz Tagle, Pablo, « Simposio: Reformas del año 2005 a la Constitución de la República de Chile », Anuario de Derechos Humanos, $n^{\circ}$ 2, 2006, p. 73-106.

Suarez, Christian, « La Constitución celda o "straight jacket constitution" y la dogmática constitucional », Universium, n² 24, 2009, p. 248-271.

Zúñiga, Francisco, « Nueva Constitución y Operación Constituyente. Algunas notas de acerca de la reforma constitucional y la Asamblea Constituyente », Estudios Constitucionales, n 1, 2013, p. 511-540.

\section{NOTAS}

1. Las críticas en este punto constituyen el núcleo principal del dilema constitucional chileno. $\mathrm{Cf}$. Ver más abajo. 


\section{AUTORES}

\section{MARÍA CRISTINA ESCUDERO ILLANES}

María Cristina Escuerdo Illanes: INAP-Universidad de Chile

mcristina.escudero@iap.uchile.cl

\section{JAIME GAJARDO FALCÓN}

Jaime Gajardo Falcón: Universidad Diego Portales

gajardofalcon@gmail.com 